\title{
Новые подходы к раннему выявлению атопических состояний у детей
}

1 - Кафедра биохимии Владимирского государственного университета им. А.Г. и Н.Г. Столетовых: 600000, Владимир, ул. Горького, 87;

2 - ФГУ "НИИ пульмонологии ФМБА России": 105077, г. Москва, ул. 11-я Парковая, 32, к. 4

\section{E.A.Zaprudnova, I.A.Klimanov, S.K.Soodaeva \\ Novel approach to early detection of atopic disorders in children}

\begin{abstract}
Summary
The aim of this work was to develop a screening method to select children with a high risk for atopic disorders. 189 school children without known atopy were evaluated using a questionnaire and measuring nitrates / nitrites in the exhaled breath condensate (EBB). These tests allowed selection of children with sings of atopy and increased EBB concentration of NO metabolites. The more signs of atopy detected, the higher and more significant EBB concentration of NO metabolites. Atopic dermatitis or allergic rhinitis alone did not accompanied by a reliable increase in EBB nitrate / nitrite concentrations but the latter became significant with combination of these disorders and sings of asthma.

Key words: nitric oxide, nitrates, nitrites, exhaled breath condensate, bronchial asthma, atopy, children.
\end{abstract}

\section{Резюме}

Целью настоящей работы была разработка метода выявления групп риска по атопии в ходе массовых скрининговых исследований среди школьников. Были обследованы 189 детей-школьников без диагностированных форм атопии, среди которых проводилось анкетирование по выявлению признаков атопии и анализ содержания нитратов и нитритов в конденсате выдыхаемого воздуха (КВВ). При сопоставлении данных анкетирования и определения метаболитов оксида азота (NO) в КВВ выделяются группы детей с признаками атопии и повышенными концентрациями метаболитов NO в КВB, причем с ростом количества выявленных признаков и при сочетании форм атопии увеличение концентрации нитратов и нитритов становится более явным и носит достоверный характер. Наличие у ребенка атопического дерматита и аллергического ринита не сопровождается достоверным увеличением концентрации нитратов и нитритов в КВВ, но в случаях сочетания этих атопических заболеваний с признаками БА повышение продукции метаболитов NO становится достоверным.

Ключевые слова: оксид азота, нитраты и нитриты, конденсат выдыхаемого воздуха, бронхиальная астма, атопия, дети.

Каждое 10-летие наблюдается примерно 2-кратное увеличение числа аллергических заболеваний [1-4]. Особое место, в связи с тяжестью заболевания, наносимым уроном здоровью и полноценному развитию личности ребенка, его способности к труду и обучению, занимает бронхиальная астма (БА) [4-6].

Рост числа атопических заболеваний стимулирует внедрение в практику новых методик ранней их диагностики [7-11]. Актуальной является разработка неинвазивных методов диагностики. Среди них перспективно исследование чувствительного биомаркера атопического воспаления, характерного для БА, - оксида азота (NO) и его метаболитов в легких [8, 12-17].

В организме оксид азота образуется из L-аргинина с участием ферментов NO-синтаз (NOS). Оценка продукции NO производится на основе хемилюминесцентного определения его концентрации в выдыхаемом воздухе. Однако внедрение метода определения выдыхаемого NO с помощью хемилюминесцентного анализатора затруднено из-за дорогостоящей аппаратуры. В то же время, нитраты и нитриты - стабильные метаболиты оксида азота, также являющиеся маркерами БА, более доступны для широкого использования [18].
NO является короткоживущей молекулой, ее период полураспада составляет, по разным источникам, 4-30 с. Оксид азота достаточно быстро выводится путем превращения в менее активные вещества $\mathrm{NO}_{2-}$ и $\mathrm{NO}_{3-}-$ ионы в присутствии $\mathrm{O}_{2}$ и $\mathrm{H}_{2} \mathrm{O}$.

$\mathrm{NO}+\mathrm{O}_{2-}>\mathrm{H}>\mathrm{ONOO}^{--}>\mathrm{NO}_{3}-$

$2 \mathrm{NO}+\mathrm{O}_{2^{-}}>2 \mathrm{NO}_{2}+\mathrm{H}_{2} \mathrm{O}^{-}>\mathrm{NO}_{3^{-}}+\mathrm{NO}_{2^{-}}+\mathrm{H}^{+}$

$2 \mathrm{NO}_{2-}>\mathrm{N}_{2} \mathrm{O}_{4}+\mathrm{H}_{2} \mathrm{O}^{-}>\mathrm{NO}_{2^{-}}+\mathrm{NO}_{2^{-}}+\mathrm{H}^{+}$

$\mathrm{NO}+\mathrm{NO}_{2^{-}}>\mathrm{N}_{2} \mathrm{O}_{3}+\mathrm{H}_{2} \mathrm{O}^{-}>2 \mathrm{NO}_{2^{-}}+2 \mathrm{H}^{+}$

$4 \mathrm{NO}_{2}+\mathrm{O}_{2}+2 \mathrm{H}_{2} \mathrm{O}^{-}>4 \mathrm{NO}_{3-}+4 \mathrm{H}^{+}$

В настоящее время распространенность атопии как таковой, подтвержденной положительными кожными пробами хотя бы к 1 из аэроаллергенов, оказывается высокой и отмечается у 40-45 \% населения, а распространенность БА, по данным международной программы по исследованию БА - ISAAC, колеблется от 2,6 до 48 \% обследованных детей. Все статистические данные, как правило, базируются на показателях, полученных при обращении пациентов в лечебные учреждения [7]. Данные, полученные таким образом, не соответствуют истинной распространенности заболевания, т. к. многие больные не обращаются в медицинские учреждения по разным причинам, особенно на ранних стадиях болезни и в легких случаях. 
Для адекватного контроля БА чрезвычайно важно своевременное выявление детей группы риска с ранними стадиями заболевания, что затруднительно из-за высоких материальных затрат на имеющиеся методы диагностики, либо из-за других проблем, связанных с их использованием (недостаточная чувствительность и др.). В результате, за границей учета остаются ранние проявления атопии. Однако многие исследователи показали, что одним из важнейших факторов формирования бронхиальной гиперреактивности является именно атопия [19-21].

Целью настоящей работы была разработка метода выявления групп риска БА в ходе массовых скрининговых исследований среди школьников.

\section{Материалы и методы}

Были обследованы 189 детей-школьников без диагностированных форм атопии, среди которых проводилось анкетирование по выявлению признаков атопии (жалоб, характерных для атопии) и анализ содержания нитратов и нитритов в конденсате выдыхаемого воздуха (КВВ). В качестве основы использованной анкеты применялся стандартизованный опросник ISSAC. В исследовании также участвовали 35 некурящих больных среднетяжелой БА (20-30 лет), у которых проводилась сравнительная оценка продукции NO и его метаболитов.

Определение NO в выдыхаемом воздухе проводили хемилюминесцентным анализатором Logan Research 2149 (Великобритания). Определение нитратов и нитритов в КВВ проводилось спектрофотометрическим методом с использованием реактива Грисса. Для оценки суммарной концентрации метаболитов NO нитраты восстанавливались из нитритов с помощью кадмиевого редуктора нитратов.

\section{Результаты и обсуждение}

Исследованиями, проведенными нами ранее, было доказано, что уровень нитратов и нитритов при обострении БА взрастает в 3-4 раза по сравнению со здоровыми испытуемыми. Поскольку для оценки продукции оксида азота нами предлагается использование метода определения его метаболитов, была проведена сравнительная оценка образования NO в выдыхаемом воздухе хемилюминесцентным методом и нитратов / нитритов - в КВВ спектрофотометрическим методом.

\section{Сравнение образования NO в выдыхаемом воздухе и нитратов, нитритов - в КВВ}

В рамках исследования был проведен сравнительный анализ содержания NO в выдыхаемом воздухе и нитратов / нитритов - в КВВ у больных БА и здоровых пациентов из группы контроля. У 32 здоровых некурящих добровольцев и 35 больных среднетяжелой БА проводилась одновременная оценка концентрации NO и нитратов / нитритов.

Как видно на рис. 1, у больных БА при обострении заболевания возрастает образование оксида азо-

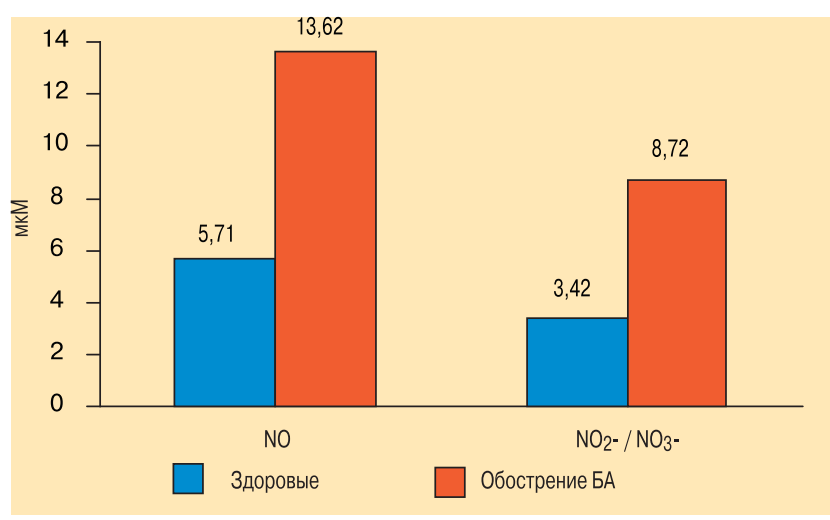

Рис. 1. Изменение показателей выдыхаемого NO и нитратов / нитритов в КВВ при обострении БА

та до 13,62 ppb, что отличается от здоровых $-5,71 \mathrm{ppb}$ $(p<0,001)$.

У этих же пациентов было отмечено возрастание уровня нитратов / нитритов в КВВ при обострении БА $(8,74 \pm 0,31$ мкМ) по сравнению со здоровыми $(3,42 \pm 0,24$ мкM); $p<0,001$.

Таким образом, в результате сравнительного анализа было установлено повышение содержания метаболитов оксида азота в КВВ при обострении БА (в 2,6 раза) и аналогичное возрастание концентрации выдыхаемого NO (в 2,4 раза). Исходя из того, что и тот, и другой показатель ( $\mathrm{NO}$ и $\mathrm{NO}_{3} / \mathrm{NO}_{2}$ ) достоверно увеличиваются при обострении атопического заболевания по сравнению с контрольной группой, оправдано использование более доступного способа оценки NO-продуцирующей функции легких.

\section{Особенности продукции нитратов / нитритов в КВВ у детей с атопией}

В результате проведенного анализа из 189 учащихся без диагностированных форм атопии нами были выявлены дети, имеющие следующие жалобы, характерные для БА: шумное дыхание и хрипы (60 человек) и затрудненное дыхание и хрипы при физической нагрузке (52), затрудненное дыхание по ночам (18) и сухой кашель по ночам (16). Известно, что при наличии атопического воспаления происходит увеличение NO-продуцирующей функции легких. Увеличение образования NO связанно с активацией индуцибельной изоформы NOS в результате транскрипции ядерного фактора kappa-B под действием провоспалительных цитокинов и эндотоксинов [5, 22-25]. При анализе содержания метаболитов NO было обнаружено повышение уровня нитратов / нитритов в КВВ у детей с наличием затрудненного дыхания и кашля по ночам в 1,6 раза по сравнению со здоровыми детьми без признаков атопии. Результаты представлены в табл. 1.

Затрудненное дыхание и хрипы были обнаружены у значительного числа $(31,7 \%)$ детей, затруднение дыхания при физической нагрузке также встречалось у $27,5 \%$ школьников. У детей этих групп не было обнаружено повышения содержания нитратов и нитритов в КВВ. Однако известно, что у многих 
Содержание суммарной конщентраџии нитратов и нитритов в КВВ у детей с признаками БА, мкМ

\begin{tabular}{|c|c|c|c|c|c|}
\hline \multirow[t]{2}{*}{ Показатели } & \multirow[t]{2}{*}{ Здоровые } & \multicolumn{4}{|c|}{ Признаки БА } \\
\hline & & $\begin{array}{c}\text { шумное дыхание } \\
\text { и хрипы }\end{array}$ & $\begin{array}{c}\text { затрудненое дыхание } \\
\text { по ночам }\end{array}$ & $\begin{array}{c}\text { затрудненное дыхание } \\
\text { и хрипы при физической нагрузке }\end{array}$ & $\begin{array}{l}\text { сухой кашель } \\
\text { по ночам }\end{array}$ \\
\hline$n$ & 61 & 60 & 18 & 52 & 16 \\
\hline$M$ & 4,294 & 5,16 & 7,04 & 5,01 & 6,805 \\
\hline$m$ & 0,21 & 0,42 & 1,23 & 0,42 & 1,28 \\
\hline$p$ & & - & $<0,001$ & - & $<0,01$ \\
\hline
\end{tabular}

детей, больных атопической БА, приступы провоцируются физической нагрузкой. Развитие бронхиальной гиперреактивности, бронхоспазма, появление гиперсекреции слизи после нагрузки связывают с липидными медиаторами аллергии, в свою очередь, инициирующими образование оксида азота $[4,16$, $22,24,26,27]$. Установлен факт повышенной способности к высвобождению лейкотриена С4 у больных БА после физической нагрузки, приводящего к немедленному бронхоспазму [7]. Следовательно, наличие затрудненного дыхания при физической нагрузке может быть связано с протеканием именно таких процессов, отсутствие же повышения содержания метаболитов NO в КВВ свидетельствует о вмешательстве и других факторов в возникновение хрипов и затруднение дыхания при физической нагрузке. Например, подобным фактором может быть низкий уровень физической тренированности. Таким образом, наличие у детей хрипов и затрудненного дыхания при физической нагрузке в меньшей степени связано с атопическим воспалением.

При сопоставлении данных анкетирования и определения метаболитов NO в КВВ выделяются группы детей с признаками атопии и повышенными концентрациями метаболитов NO в КВB, причем с ростом количества выявленных признаков и при сочетании форм атопии, увеличение концентрации нитратов и нитритов становится более явным и носит достоверный характер (рис. 2).

Как видно из рис. 2, наличие 1-2 признаков БА не сопровождается достоверными изменениями в содержании нитратов и нитритов в КВВ у детей $(4,72 \pm$

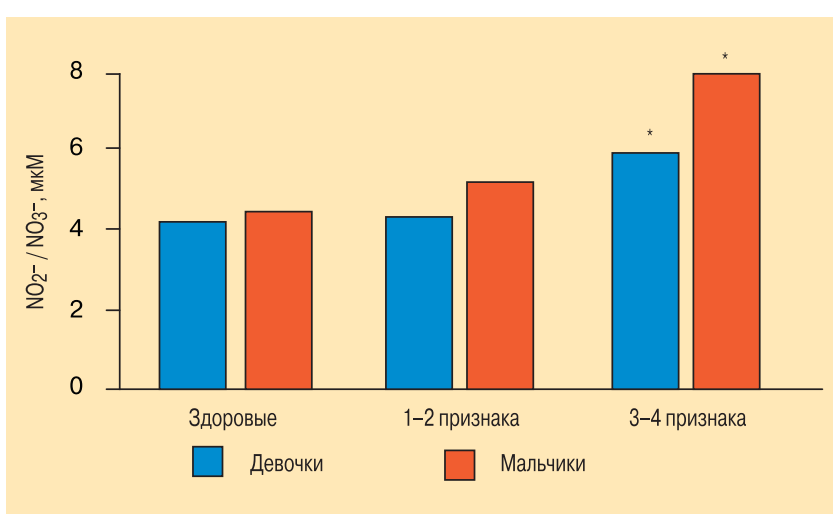

Рис. 2. Уровень нитратов и нитритов в КВВ в зависимости от количества признаков БА

Примечания: * - отличия достоверны по сравнению со здоровыми, $p<0,05$
0,75 мкмоль / л, по сравнению с 4,29 \pm 0,21 мкмоль / л в контрольной группе). При наличии 3-4 признаков БА у детей отмечается достоверное увеличение концентрации нитратов и нитритов в $\mathrm{KBB}(M=$ 6,82 мкм / л, по сравнению с $M=4,29$ мкм / л в контрольной группе). Дети, отмечающие у себя 3-4 признака БА (6,3 \% (12 человек) из всех обследованных школьников) составляют группу риска БА, поскольку проявления БА сопровождаются повышенным образованием метаболитов NO в нижних дыхательных путях, что свидетельствует о запуске молекулярных механизмов патогенеза БА. На рис. 2 также видно, что более высокие показатели суммарной концентрации нитратов и нитритов наблюдаются у мальчиков. Среди мальчиков с признаками БА наиболее часто встречалось одновременно 3-4 признака $(11,54 \%)$, тогда как для девочек такое количество признаков менее характерно (10,7 \%). Подобное распределение признаков согласуется с общей статистической картиной респираторной заболеваемости, показывающей превалирующее развитие заболеваний дыхательной системы среди мальчиков. Так, некоторыми авторами указывается, что детская и подростковая астма наблюдается преимущественно у мальчиков и лишь в 20-40 лет распространенность становится одинаковой [28].

В результате исследования у школьников были обнаружены также и признаки других форм атопии атопического дерматита (АД) и аллергического ринита (АР). Результаты анкетирования показали, что признаки АД (наличие зудящей сыпи без поставленного диагноза дерматита) встречались у 19 девочек и 15 мальчиков. Признаки АР (чихание, насморк, когда нет простуды, а также зуд в глазах и слезотечение) были отмечены у 110 школьников, 54 из них мальчики, 56 - девочки. Результаты анализа уровня нитратов и нитритов в КВВ в этих группах представлены в табл. 2.

Определение концентрации метаболитов NO в этих группах детей не показало достоверных отличий от контрольной группы школьников. Эти данные подтверждают тот факт, что наличие метаболитов NO в КВB является биомаркером атопического воспаления именно в легких.

Наличие у ребенка АД и АР не сопровождается достоверным увеличением концентрации нитратов и нитритов в КВВ, но в случае сочетания этих атопических заболеваний с признаками БА повышение продукции метаболитов NO становится достовер- 
Таблица 2

Содержание суммарной конщентрации нитратов и нитритов в КВВ у детей с признаками АД и АР, мкМ

\begin{tabular}{|l|c|c|c|} 
Показатели & Здоровые & Признаки АД & Признаки АР \\
\hline $\boldsymbol{n}$ & 61 & 34 & 110 \\
\hline $\boldsymbol{M} \pm \boldsymbol{m}$ & $4,29 \pm 0,21$ & $5,17 \pm 0,46$ & $4,59 \pm 0,23$ \\
\hline
\end{tabular}

Примечание: различия при сравнении со здоровыми не достоверны.

ным (6,75 \pm 0,79 мкм / л, по сравнению с 4,29 \pm 0,21 мкм / л - в контрольной группы).

Таким образом, неинвазивный метод определения метаболитов NO в КВB является чувствительным и информативным для выявления детей с высоким риском формирования БА и может быть рекомендован для использования в практике медицинских обследований.

\section{Литература}

1. Петровская Ю.А., Петровский Ф.И., Кулманакова И.М., Огородова Л.М. Взаимосвязь синтеза оксида азота с некоторые количественными показателями атопического воспаления в семьях детей, больных бронхиальной астмой. Биол. и мед. 2000; 129 (прил. № 1): 38-39.

2. Хаитов Р.М., Лусс Л.В., Арипова И.В. и др. Распространенность симптомов бронхиальной астмы, аллергического ринита и аллергодерматозов у детей по критериям ISAAC. Аллергия, астма и клин. иммунол. 1998; 9: $58-69$.

3. Чучалин А.Г., Сулаквелидзе И.В. Проблемы аспириновой астмы. Тер. арх. 1988; 10: 92-97.

4. Чучалин А.Г. Бронхиальная астма. М.; 1997; т. 1, 2.

5. Невзорова В.А., Елисеева Е.В., Зуга М.В. Нитрооксидергические механизмы регуляции бронхов и их значение в патогенезе бронхиальной астмы. Тер. арх. 1998; 3: $13-18$.

6. Cookson W. Polygenes. Asthma, and atopy. In from genetics to quality of life. In: XV World congress of asthmology. Seattle; 1996. 15-19.

7. Бронхиальная астма. Глобальная стратегия. Пульмонология 1996; Прил.

8. Вознесенский Н.А. Выдыхаемый оксид азота - биомаркер бронхиальной астмы: Автореф. дис. ... канд. мед. наук. М.; 2000.

9. Barnes P.J., Liu S. Regulation of pulmonary vascular tone. Physiol. Rev. 1995; 47: 87-131.

10. Uchida Y., Endo T., Iijima H. et al. Increased production of nitric oxide in the immediate and late asthmatic responses in models of guinea pig experimental asthma. Nihon Kyobu Shikkan Gakkai Zasshi 1995; (Suppl. 33): 190-192.

11. Gustafsson L.E., Leone A.M., Persson M.G. et al. Endogenous nitric oxide is present in the exhaled air of rabbits, guinea pigs and humans. Biochem. Biophys. Res. Commun. 1991; 181 (2): 852-857.
12. Alving K., Weitzberg E., Lundberg J.M. Increased amount of nitric oxide in exhaled air of asthmatics. Eur. Respir. J. 1993; 6 (9): 1368-1370.

13. Goldstein J.A. Nitroglycerin therapy of asthma. Chest 1984; 85 (3): 449.

14. Kharitonov S.A., Yates D., Barnes P.J. Increased nitric oxide in exhaled air of normal human subjects with upper respiratory tract infections. Eur. Respir. J. 1995; 8: 295-297.

15. Liew F.Y., Cox P.P. Nonspecific resistance mechanisms: the role of nitric oxide. Immunol. Today 1991; 12: 17-21.

16. Persson M.G., Wikiund N.P., Gustafsson L.E. Endogenous nitric oxide in single exhalation, and the change during execise. Rev. Respir. Dis. 1993; 148: 1210-1214.

17. Ueno T., Kataoka M., Hirano A. et al. Inflammatory markers in exhaled breath condensate from patients with asthma. Respirology. 2008; 13 (5): 654-663.

18. Реутов В.П., Сорокина Е.Г. NO-синтазная и нитритредуктазная компоненты цикла оксида азота. Биохимия 1998; 63 (7): 1029-1040.

19. Смоленов И.В., Машукова Н.Г. Первичная профилактика бронхиальной астмы у детей. Consillium medicum 2001; Прил.: 17-21.

20. Елисеева Е.В. Реакция нитрооксидазы и тучных клеток органов дыхания на вещества адренергического действия в норме и при экспериментальной БА: Автореф. дис. ... д-ра мед. наук. Владивосток; 1997.

21. Каганов С.Ю., Дюрич В.М., Вельтищев Ю.Е. и др. (ред.). Организация работы пульмонологического педиатрического центра. М.: Медицина; 1982.

22. Мотавкин П.А., Гельцер Б.И. Клиническая и экспериментальная патофизиология легких. М.; 1998.

23. Barnes P.J. Transcription factors in airway diseases. Lab. Invest. 2006; 86 (9): 867-872.

24. Nathan $C$., Xie $Q$. Regulation of biosynthesis of nitric oxide. J. Biol. Chem. 1994; 269 (3): 13725-13728.

25. Raychaudhuri B., Dweik K., Connors M.J. et al. Nitric oxide blacks nuclear factor-kappa B activation in alveolar macrophages. Am. J. Respir. Cell Mol. Biol. 1999; 21 (3): 311-316.

26. Beck K.C. Control of airway function during and after exercise in asthmatics. J. Med. Sci. Sports Exerc. 1999; 31 (Suppl. 1): S4-S11.

27. Kharitonov S.A., Barnes P.J. Clinical aspects of exhaled nitric oxide. Eur. Respir. J. 2000; 16 (4): 781-792.

28. Огородова Л.М., Астафьева Н.Г. Факторы риска астмы. Consilium Medicum 2001; Прил.: 4-8.

\section{Информация об авторах}

Запруднова Елена Александровна - к. б. н., доцент кафедры биологии Владимирского государственного университета; тел.: (4922) 47-97-85; e-mail: eazaprudnova@mail.ru

Соодаева Светлана Келдибековна - д. м. н., проф., зав. лабораторией клинической и экспериментальной биофизики ФГУ "НИИ пульмонологии ФМБА России"; тел. / Факс: (495) 465-52-64; e-mail: soodaeva@mail.ru Климанов Игорь Александрович - к. М. н., ст. науч. сотрудник лаборатории клинической и экспериментальной биофизики ФГУ "НИИ пульмонологии ФМБА России"; тел. / Факс: (495) 465-52-64; e-mail: igorklimanov @yandex.ru

Поступила 27.09.10 (c) Коллектив авторов, 2010 удк 616-056.3-053.2-07:616.24-008.7-074 